\title{
Population-Based Screening and Eradication of Helicobacter pylori in a Resource-Limited Population of Sub-Saharan Africa
}

\section{Yang Jae Lee}

Washington University in Saint Louis School of Medicine

Ibrahim Ssekalo

Empower Through Health

Rauben Kazungu

Empower Through Health

Timothy S. Blackwell

University of Tennessee College of Medicine

\section{Peter Muwereza}

Ministry of Health

\section{Yuefeng Wu}

University of Missouri-St. Louis

Jose Bernardo Saenz ( $\nabla$ saenzj@wustl.edu )

Washington University in Saint Louis School of Medicine https://orcid.org/0000-0002-0390-633X

\section{Research article}

Keywords: Helicobacter pylori, dyspepsia, prevalence, Uganda

Posted Date: September 15th, 2020

DOl: https://doi.org/10.21203/rs.3.rs-65425/v1

License: (9) This work is licensed under a Creative Commons Attribution 4.0 International License. Read Full License 


\section{Abstract}

Background: Helicobacter pylori (H. pylori) infection is a common cause of chronic dyspepsia worldwide. Its prevalence in the developing world remains understudied, however. Given that $H$. pylori is the most significant risk factor for developing gastric cancer, an accurate assessment of the effectiveness of population-based screening and eradication of $H$. pylori is warranted. The objectives of this study were to determine the prevalence of $H$. pylori, to identify risk factors associated with $H$. pylori colonization, and to assess the efficacy of triple therapy on $H$. pylori eradication within a region of sub-Saharan Africa.

Methods: We administered a dyspepsia questionnaire to 376 randomly selected adult residents of the Namutumba District in Uganda. Participants submitted a stool sample for $H$. pylori fecal antigen testing. H. pylori-positive participants were given standard triple therapy. The efficacy of triple therapy on H. pylori eradication was established by fecal $H$. pylori antigen testing and improvement in dyspepsia scores after treatment. Dyspeptic, H. pylori-negative participants were administered daily omeprazole for one month. Logistic regression analyses were used to identify factors associated with $H$. pylori positivity, chronic dyspepsia, and H. pylori eradication failure.

Results: The prevalence of $H$. pylori within the study population was $48 \%$. A higher level of education was significantly associated with $H$. pylori positivity. $87 \%$ of study participants reported at least one symptom of dyspepsia, with $43 \%$ reporting moderate or severe dyspepsia. Dyspepsia severity was independent of $H$. pylori status. Standard triple therapy resulted in $\sim 90 \%$ eradication. Missing four or more doses of the triple therapy regimen was significantly associated with $\mathrm{H}$. pylori eradication failure.

Conclusions: Chronic dyspepsia is a common complaint in this sub-Saharan population but is not by itself a defining feature of $H$. pylori positivity. Clinical suspicion for $H$. pylori within this population should nonetheless remain high, given the high prevalence of positivity among all those with dyspepsia, including many with relatively mild dyspeptic symptoms. Population-based screening and adherence to standard triple therapy are effective at eradicating $H$. pylori within this region.

Trial Registration: This study was registered in ClinicalTrials.gov (TRN: NCT04525664, registered 24 August 2020 - Retrospectively registered, https://clinicaltrials.gov/ct2/show/NCT04525664). This study adheres to CONSORT guidelines.

\section{Background}

Helicobacter pylori (H. pylori) is one of the world's most successful pathogens, affecting approximately half of the global population ${ }^{1}$. Its success in part relies on its ability to establish chronic infection and persist within the hostile environment of the human stomach ${ }^{2}$. Classified as a human carcinogen ${ }^{3}, H$. pylori remains the most significant and modifiable risk factor for the development of gastric cancer, one of the leading global causes of cancer-related deaths ${ }^{4}$. While treatment regimens over the past few 
decades have significantly improved global eradication rates ${ }^{5}, H$. pylori remains a ubiquitous pathogen that contributes to significant morbidity and mortality worldwide ${ }^{1}$.

In particular, $H$. pylori disproportionately affects the developing world and remains a leading cause of disability adjusted life years (DALY) in low-income countries ${ }^{6}$. The "test-and-treat" strategy that guides management of $H$. pylori infection ${ }^{7}$ assumes the ability to accurately diagnose $H$. pylori through invasive or non-invasive means, which may not exist or be readily accessible in countries with limited testing capacity. In addition, the predictive value of these diagnostic tests is in part dependent on the prevalence of $\mathrm{H}$. pylori within the population, which is often unknown or inferred from limited studies. Moreover, most studies determine the regional prevalence based on symptomatic residents presenting to a hospital or health center ${ }^{8-11}$. If we consider that most chronically infected patients exhibit few if any symptoms ${ }^{12}$ and take into account the limited access to health care facilities in underserved or rural areas, it stands to reason that the reported prevalence of $H$. pylori within the general population has been inaccurately assessed in the developing world.

Central to the effective management of $H$. pylori infection is a heightened clinical suspicion for its variable, and often mild, symptomatic presentation ${ }^{12}$. H. pylori remains a significant cause of chronic dyspepsia, a complex set of gastrointestinal symptoms that accounts for frequent heath care visits and substantial $\operatorname{costs}^{13}$. Indeed, recent guidelines emphasize the importance of testing for and treating $H$. pylori when managing chronic dyspepsia ${ }^{14}$. It remains to be seen, however, whether these guidelines effectively translate to the developing world. Studies demonstrate that the prevalence of dyspepsia on the African continent is highly variable ${ }^{15-17}$. However, most if not all studies in the developing world directly correlating active $H$. pylori infection to dyspepsia have focused on patients presenting to a hospital or health care setting $8,11,18-22$, and the true prevalence of $H$. pylori and its correlation with dyspepsia within the general population is not known. The empiric treatment of chronically dyspeptic patients with inconsistent regimens to eradicate H. pylori often replaces the recommended "test-and-treat" strategy, contributing to antibiotic resistance and limiting efficacy ${ }^{23}$. The medical and economic burden of chronic dyspepsia in the developing world cannot be mitigated, therefore, without accurately determining the prevalence of $H$. pylori, identifying patients at risk of $H$. pylori infection, and evaluating treatment efficacy.

In this study, we use a survey questionnaire to examine the prevalence and severity of chronic dyspepsia among residents of the Namutumba district in eastern Uganda. Using fecal antigen testing, we also determine the prevalence of $H$. pylori within this population and identify risk factors that predict $H$. pyloriinduced dyspepsia. Finally, we assess the efficacy of standard triple therapy for $H$. pylori eradication and symptomatic improvement of chronic dyspepsia.

\section{Methods}

\section{Ethical Considerations}


All study participants provided written informed consent. This study was approved by the Institutional Review Board at the Washington University in St. Louis School of Medicine (U.S.A.) and by the Ugandan National Council of Science and Technology (UNCST) and The AIDS Support Organization (TASO; Uganda).

\section{Inclusion/Exclusion Criteria}

Adult residents (aged 18 or older) of the Namutumba District in eastern Uganda were randomly selected between October 2018 and May 2019 using the lot quality assurance sampling (LQAS) method ${ }^{24}$. Briefly, households were selected through random sampling, and one adult in each household was asked to participate in the study. Participants who provided informed consent completed a questionnaire conducted by a research study member, in either English or the local dialect, Lusoga. Participants also agreed to provide a stool sample for fecal H. pylori antigen testing (OnSite ${ }^{\text {TM }}$ H. pylori Antigen Rapid Test; CKT Biotech, Poway, CA). Any participants unwilling or unable to provide informed consent, less than 18 years of age, or who had used proton pump inhibitors and/or antibiotics within the past month were excluded. Participants could withdraw from the study at any point and for any reason.

\section{Study Design}

All participants providing informed consent were administered a survey questionnaire, which also included the Short-Form Leeds Dyspepsia Questionnaire ${ }^{25}$ (SFLDQ; see Supplemental Table 1). Participants positive for $\mathrm{H}$. pylori by fecal antigen testing were offered clarithromycin (500 $\mathrm{mg}$ per os twice daily), amoxicillin ( $1 \mathrm{~g}$ per os twice daily), and omeprazole (40 mg per os twice daily) for 14 consecutive days. Participants met with research study members three to five times during their treatment regimen for pill counts and to report any adverse effects. One month following the completion of their treatment regimen, participants answered a follow-up questionnaire (Supplemental Table 2) and repeated a fecal $H$. pylori antigen test. Those who were still positive for $H$. pylori after repeat fecal antigen testing were referred to a clinic for an additional 14 days of quadruple therapy, consisting of tetracycline (500 mg per os four times daily), metronidazole (250 mg per os four times daily), bismuth subsalicylate ( $525 \mathrm{mg}$ per os four times daily), and omeprazole (40 mg per os twice daily). Participants with chronic dyspepsia scores of 8 or greater, as determined by the SFLDQ, and who were negative for $\mathrm{H}$. pylori by fecal antigen testing, were offered daily omeprazole $(20 \mathrm{mg})$ for one month. Their overall symptomatic improvement was reassessed by a research study member one month after the completion of the omeprazole regimen.

\section{Dyspepsia Severity Assessment}

All consenting participants completed a questionnaire, which included the SFLDQ. Based on the summed total score from the SFLDQ (out of 32), participants were categorized as either having no dyspepsia (score of 0 ), mild dyspepsia (score of 1-8), moderate dyspepsia (score of 9-15), or severe dyspepsia (score > 15). Participants who were negative for H. pylori and had a dyspepsia score of 8 or greater were offered daily omeprazole $(20 \mathrm{mg})$ for one month. Dyspepsia scores for participants who tested positive for $H$. pylori were calculated before triple therapy and one month after completion of the treatment regimen. 


\section{Modeling Dyspepsia Severity as a Function of Age}

The probability of dyspepsia as a function of age among H. pylori-positive or -negative participants was based on multinomial and ordinal logistic regression models, using the R packages nnet and MASS. Treating the severity of dyspepsia (i.e., none, mild, moderate, or severe) as ordinal categorical data, the model used no dyspepsia as the baseline, and the logarithm of the ratio of the probability for different levels of dyspepsia was modeled by a linear function of age.

\section{Statistical Analyses}

All statistical analyses were done using the R 4.0 statistical package. Log linear models were used to study the relationship between $H$. pylori status and categorical baseline characteristics (Table 1). The associations between $H$. pylori status and dyspepsia severity as well as dyspepsia symptomatic components (Supplemental Table 3) were determined by logistic regression models. The relationship between dyspepsia severity and categorical baseline characteristics among $H$. pylori-negative participants (Table 2) was determined using log linear models. To generate mosaic plots correlating dyspeptic symptoms (Fig. 5), Pearson residuals were calculated to visualize the correlations between each pair of symptoms. Predictors of $H$. pylori eradication failure (Table 3 ) were modeled and tested by log linear models. Dyspepsia scores among $H$. pylori-positive participants before and after treatment (Fig. 6) were compared using a paired $t$-test. For all analyses, $p<0.05$ was considered statistically significant.

\section{Results}

Prevalence of and risk factors for $\mathrm{H}$. pylori within the Namutumba District

Of the 400 adult participants contacted for the study, 376 (94\%) met the inclusion criteria, completed the survey questionnaire, and provided a stool sample for fecal $\mathrm{H}$. pylori antigen testing. The majority of excluded participants declined to complete the survey questionnaire and/or provide a stool sample (Fig. 1). Table 1 demonstrates the baseline characteristics for the study population and a comparison between $H$. pylori-positive and -negative participants. 
Table 1

Participant characteristics.

\begin{tabular}{|c|c|c|c|}
\hline Characteristic & $\begin{array}{l}\text { H. pylori } \\
\text { positive } \\
(n=181)\end{array}$ & $\begin{array}{l}\text { H. pylori } \\
\text { negative } \\
(n=195)\end{array}$ & $\begin{array}{l}P \\
\text { value }\end{array}$ \\
\hline Age in years, median (IQR) & $45(23)$ & $40(25)$ & 0.3461 \\
\hline Gender, n (\%) & $124(68)$ & $138(70.8)$ & 0.6338 \\
\hline Female & $57(32)$ & $57(29.2)$ & \\
\hline \multicolumn{4}{|l|}{ Male } \\
\hline Marital status, n (\%) & $151(83.4)$ & $166(85.1)$ & 0.7889 \\
\hline Married or cohabitating & $7(3.9)$ & $9(4.6)$ & \\
\hline Single and never married & $6(3.3)$ & $7(3.6)$ & \\
\hline Widowed & $17(9.4)$ & $13(6.7)$ & \\
\hline \multicolumn{4}{|l|}{ Separated } \\
\hline Highest level of education, $\mathrm{n}(\%)$ & $43(23.8)$ & $68(34.9)$ & 0.0443 \\
\hline No education & $95(52.5)$ & $93(47.7)$ & \\
\hline Primary & $43(23.7)$ & $34(17.4)$ & \\
\hline \multicolumn{4}{|l|}{ Secondary or above } \\
\hline Proximity to health services, $\mathrm{n}(\%)$ & $136(75.1)$ & $130(66.7)$ & 0.2092 \\
\hline Less than $5 \mathrm{~km}$ & $38(21)$ & $56(28.7)$ & \\
\hline Between $5 \mathrm{~km}$ and $10 \mathrm{~km}$ & $7(3.9)$ & $8(4.1)$ & \\
\hline \multicolumn{4}{|l|}{ More than $10 \mathrm{~km}$} \\
\hline Smoking status, n (\%) & $3(1.6)$ & $3(1.5)$ & 0.2208 \\
\hline Cigarettes & $2(1.1)$ & $0(0)$ & \\
\hline Marijuana & $0(0)$ & $1(0.5)$ & \\
\hline Other & $1(0.6)$ & $0(0)$ & \\
\hline Don't know & & & \\
\hline
\end{tabular}




\begin{tabular}{|llll|}
\hline Characteristic & $\begin{array}{l}\text { H. pylori } \\
\text { positive } \\
(\mathbf{n = 1 8 1 )}\end{array}$ & $\begin{array}{l}\text { H. pylori } \\
\text { negative } \\
(\mathbf{n}=195)\end{array}$ & $\begin{array}{c}\boldsymbol{P} \\
\text { value }\end{array}$ \\
\hline Alcohol use, $\mathrm{n}(\%)$ & $20(11)$ & $36(18.5)$ & 0.1115 \\
1 day per week or less & $5(2.8)$ & $3(1.5)$ & \\
2 days per week & $3(1.6)$ & $4(2.0)$ & \\
3 days per week & $10(5.5)$ & $4(2.0)$ & \\
4 days per week or more & & & 0.081 \\
\hline NSAID use, $\mathrm{n}$ (\%) & $49(27.1)$ & $37(19)$ & 0.4157 \\
\hline Number of persons per household, median (IQR) & $6(4)$ & $7(4.5)$ & 0.2459 \\
\hline Number of children in household, median (IQR) & $4(3)$ & $4(3.5)$ & \\
\hline $\begin{array}{l}\text { Households with pets/livestock within living } \\
\text { quarters, }\end{array}$ & $44(24.3)$ & $45(23.1)$ & \\
$\mathrm{n}$ (\%) & & & \\
\hline
\end{tabular}

IQR: Interquartile range.

\section{H. pylori: Helicobacter pylori}

NSAID: Non-steroidal anti-inflammatory drug.

At baseline, there was no significant difference between $H$. pylori-positive and $H$. pylori-negative participants in most of the demographic and socioeconomic factors analyzed. Of note, those with higher levels of education attained (secondary education and above) were significantly more likely to be positive for $H$. pylori compared to those with no formal education or having only achieved a primary education ( $p$ $=0.0443)$. While there was a trend toward higher NSAID use among $H$. pylori-positive participants, the difference was not statistically significant $(p=0.081)$.

The point prevalence of $H$. pylori within this study population was $48 \%$ (Fig. 1). The magnitude of $H$. pylori cases varied regionally within the Namutumba District, with the Namutumba sub-county accounting for the highest number of cases and the Nabweyo sub-county recording the fewest number of cases (Fig. 2A). When controlling for the number of participants sampled from each sub-county, the prevalence of $H$. pylori ranged from $22-68 \%$, with the Namutumba sub-county again representing the highest density of H. pylori cases within the district (Fig. 2B). No statistically significant differences in $H$. pylori prevalence were observed between any of the sub-counties (not shown).

Dyspepsia among H. pylori-positive and -negative participants 
Given the prevalence of $H$. pylori within this population and the variable symptomatology associated with H. pylori infection ${ }^{12,26}$, we sought to determine whether the presence or severity of dyspepsia correlated with $H$. pylori positivity. We also aimed to identify potential dyspeptic symptoms that might predict $H$. pylori positivity. To quantify the degree of dyspepsia within our study population, we assigned each participant a dyspepsia score based on the SFLDQ, a questionnaire to quantitatively categorize dyspepsia severity ${ }^{25}$ that has been validated among African patients ${ }^{27}$. Of the 376 participants, 326 (86.7\%) reported some degree of dyspepsia (SFLDQ score >0; Figs. 1 and 3A). Most dyspeptic participants reported mild dyspepsia (SFLDQ score 1-8), with similar proportions reporting moderate (SFLDQ score 9-15) and severe dyspepsia (SFDLQ score $>15$ ). The severity of dyspepsia was similar between $H$. pylori-positive and -negative participants (Figs. 3B-C). Accordingly, the median dyspepsia scores did not significantly differ based on $H$. pylori positivity (median SFLDQ score 8 vs median SFLDQ score 7; Supplemental Table 3). In addition, H. pylori-positive participants were not significantly more likely to report indigestion, heartburn, regurgitation, and/or nausea, the four symptom components of the SFLDQ, compared to H. pylori-negative participants.

As per the most recent guidelines ${ }^{14}$, chronically dyspeptic participants found to be negative for $H$. pylori completed one month of a daily proton pump inhibitor (i.e., omeprazole). Of participants who reported some degree of dyspepsia and who were negative for H. pylori $(n=168)$, only those with dyspepsia scores of 8 or above $(n=91)$ were selected to undergo daily omeprazole therapy (Fig. 1$)$. After one month of omeprazole, a significant majority of dyspeptic participants reported subjective improvement in their dyspepsia (not shown).

Among H. pylori-negative participants, the presence or severity of dyspepsia was not significantly associated with various demographic, socio-economic, or behavioral characteristics that have been previously shown to correlate with dyspepsia, including gender, level of education, alcohol use, or NSAID use $^{28}$ (Table 2). 
Table 2

Dyspepsia severity among Helicobacter pylori-negative participants.

\begin{tabular}{|c|c|c|c|c|c|}
\hline Characteristic & $\begin{array}{l}\text { None } \\
(n=27)\end{array}$ & $\begin{array}{l}\text { Mild } \\
(n=89)\end{array}$ & $\begin{array}{l}\text { Moderate } \\
(n=45)\end{array}$ & $\begin{array}{l}\text { Severe } \\
(n=34)\end{array}$ & $P$ value \\
\hline Female, n (\%) & $17(63)^{\star}$ & $59(66)^{\star \star}$ & $35(78)^{\#}$ & $27(79)^{\# \#}$ & 0.2665 \\
\hline Male, n (\%) & $10(37)^{\star}$ & $30(34)^{\star \star}$ & $10(22)^{\#}$ & $7(21)^{\# \#}$ & $\begin{array}{l}\text { *0.4076 } \\
\star 0.4478 \\
{ }^{\#} 0.3448 \\
{ }^{\# \#} 0.3000\end{array}$ \\
\hline Level of education, $n$ & 10 & 26 & 16 & 16 & 0.1373 \\
\hline No education & 16 & 43 & 20 & 14 & \\
\hline $\begin{array}{l}\text { Primary } \\
\text { Secondary or above }\end{array}$ & 1 & 20 & 9 & 4 & \\
\hline Alcohol use, $n$ & 24 & 64 & 35 & 25 & 0.5747 \\
\hline 1 day per week or less & 1 & 18 & 9 & 8 & \\
\hline 2 days per week & 1 & 2 & 0 & 1 & \\
\hline \multicolumn{6}{|l|}{4 days per week or more } \\
\hline NSAID use, n (\%) & $4(15)$ & $13(15)$ & $13(29)$ & $7(20)$ & 0.2267 \\
\hline Use of herbal medicines, $n$ & 2 & 19 & 13 & 11 & 0.0668 \\
\hline Yes & 24 & 68 & 31 & 22 & \\
\hline No & & & & & \\
\hline
\end{tabular}

* Comparison between males and females with no dyspepsia (dyspepsia score of 0).

** Comparison between males and females with mild dyspepsia (dyspepsia score of 1-8).

\# Comparison between males and females with moderate dyspepsia (dyspepsia score of 9-15).

\#\# Comparison between males and females with severe dyspepsia (dyspepsia score > 15).

While there appeared to be greater dyspepsia severity among women compared to men, this was not statistically significant. However, the probability of developing severe dyspepsia among all participants increased with age, while the probability of having mild dyspepsia decreased with age (Fig. 4A). Similar 
findings were seen among H. pylori-negative participants (Fig. 4B). Interestingly, the probability of being free of dyspepsia (i.e., SFLDQ score of 0 ) increased with age among H. pylori-positive participants, while the probability of having severe dyspepsia was largely unchanged as a function of age (Fig. 4C). Within our study population, therefore, the probability of developing severe dyspepsia or being free of dyspepsia could be modeled as a function of age, based on H. pylori status (Supplemental Table 4; see Methods).

The SFLDQ relies on assessing the frequency of four symptom components, including indigestion, heartburn, regurgitation, and nausea. While no individual symptom was significantly associated with $H$. pylori positivity (Supplemental Table 3), there was a strong correlation among the frequency of dyspeptic symptoms within the sampled population. Among all participants, those reporting one symptom from the SFLDQ were significantly more likely to report a separate symptom, regardless of the symptom. Similarly, participants reporting the absence of one symptom were significantly more likely to also report the absence of a different symptom. These correlations were modeled and found to be highly statistically significant across all combinations of symptoms (Figs. 5A-F) and were independent of gender (Supplemental Fig. 1). For example, heartburn and indigestion correlated strongly $\left(p=5.01 \times 10^{-14}\right.$; Fig. $5 \mathrm{~A}$ ), such that participants with frequent heartburn (i.e., once a day or more) were also significantly more likely to report frequent indigestion. Similarly, those reporting no heartburn were also significantly more likely to report no indigestion.

\section{Efficacy of triple therapy on $\mathrm{H}$. pylori eradication and dyspepsia severity}

To determine the efficacy of triple therapy on H. pylori eradication, all participants who tested positive for H. pylori, regardless of the presence of dyspepsia, underwent 14 days of standard treatment (see Methods). Of the 181 participants who were positive for $H$. pylori, 171 (94.4\%) began triple therapy. Nine participants were lost to follow-up prior to starting treatment, and one participant declined treatment (Fig. 1). Participants undergoing treatment met with study team members three to five times during their 14-day regimen to assess for symptoms, adverse reactions, and medication compliance. Symptoms experienced during the treatment regimen are listed in Supplemental Table 5. No adverse events were reported.

Approximately one month after completing treatment, participants met with study team members to complete a follow-up questionnaire and to submit a stool sample for fecal $\mathrm{H}$. pylori antigen testing. Of the 171 participants who underwent treatment, 165 (96.4\%) filled the follow-up questionnaire and submitted a stool sample at the completion of the study. Five participants who completed treatment were lost to follow-up and did not complete a follow-up questionnaire or undergo repeat fecal antigen testing. One participant refused to complete the follow-up questionnaire and provide a stool sample after completing triple therapy (Fig. 1).

Of the $165 \mathrm{H}$. pylori-positive participants who completed therapy and post-treatment testing, 148 were negative by fecal antigen testing at the completion of the study, for an eradication efficacy of $89.7 \%$ (Fig. 6A). 17 participants (10.3\%) were still positive, and these participants were provided with quadruple 
therapy (see Methods). Triple therapy resulted in a significant improvement in dyspepsia severity, decreasing from a mean dyspepsia score of 8.8 before therapy to a mean score of 1.7 after therapy (Fig. 6B; $p$ <.0001). Of various risk factors analyzed, only participants who missed four or more doses of their medications during the course of the triple therapy regimen were significantly more likely to fail $H$. pylori eradication ( $p=0.0415$; Table 3$)$. 
Table 3

Factors associated with Helicobacter pylori eradication.

\begin{tabular}{|c|c|c|c|}
\hline Characteristic & $\begin{array}{l}\text { Fecal antigen } \\
\text { negative } \\
(n=148)\end{array}$ & $\begin{array}{l}\text { Fecal antigen } \\
\text { positive } \\
(n=17)\end{array}$ & $\begin{array}{l}P \\
\text { value }\end{array}$ \\
\hline Female gender, $\mathrm{n}(\%)$ & $103(70)$ & $9(53)$ & 0.3981 \\
\hline Level of education, $n$ & 38 & 3 & 0.4342 \\
\hline No education & 74 & 11 & \\
\hline Primary & 34 & 2 & \\
\hline Secondary & 2 & 1 & \\
\hline \multicolumn{4}{|l|}{ Tertiary } \\
\hline Alcohol use, $n$ & 112 & 16 & 0.4185 \\
\hline None & 18 & 1 & \\
\hline 1 day per week or less & 5 & & \\
\hline 2 days per week & 3 & & \\
\hline 3 days per week & 10 & & \\
\hline \multicolumn{4}{|l|}{4 days per week or more } \\
\hline NSAID use, n (\%) & $42(28)$ & $2(12)$ & 0.1415 \\
\hline Use of other antibiotics, $\mathrm{n}(\%)$ & $37(25)$ & $5(29)$ & 0.6090 \\
\hline Yes & $80(54)$ & $6(35)$ & \\
\hline No & $31(21)$ & $6(35)$ & \\
\hline \multicolumn{4}{|l|}{ Don't know } \\
\hline \multirow{2}{*}{$\begin{array}{l}\text { Experienced new symptoms during } \\
\text { treatment, } \mathrm{n}(\%)\end{array}$} & $84(57)$ & $11(65)$ & 0.9384 \\
\hline & $63(42)$ & $6(35)$ & \\
\hline No & \multicolumn{3}{|l|}{$1(1)$} \\
\hline \multicolumn{4}{|l|}{ Don't know } \\
\hline Number of missed doses, $\mathrm{n}(\%)$ & $146(99)$ & $15(88)$ & 0.0415 \\
\hline $0-4$ & $2(1)$ & $2(12)$ & \\
\hline More than 4 & & & \\
\hline
\end{tabular}

\section{Discussion}


Although $\mathrm{H}$. pylori is regarded as a ubiquitous pathogen, an accurate determination of its prevalence in the developing world, particularly on the African continent, has been hampered by a lack of data or by limited studies focusing on symptomatic individuals presenting to a health care facility ${ }^{1,8-11,29,30}$. These estimates are often used to extrapolate the prevalence within the general population and may not account for inadequate access to health care and limited use of health resources in these countries ${ }^{31,32}$. This study determined the prevalence of $\mathrm{H}$. pylori within the general population of a rural district of eastern Uganda by fecal antigen testing, an accurate, non-invasive, convenient, and inexpensive method for diagnosing $H$. pylori infection ${ }^{33-36}$. $48 \%$ of participants in the Namutumba district tested positive for H. pylori, a prevalence that is slightly lower than the reported prevalence in other African countries ${ }^{1,17}$, including the neighboring Democratic Republic of $\mathrm{Congo}^{37}$, though consistent with the reported prevalence in Kenya ${ }^{38}$. Of note, this prevalence was higher than that reported for symptomatic patients presenting to a hospital in western Uganda ${ }^{11}$. However, those studies relied on detection of $H$. pylori in symptomatic patients presenting to a health care facility, which may have underestimated the true burden of disease.

The reasons for the variation in regional $H$. pylori prevalence within the Namutumba district are unclear. The Namutumba sub-county had the highest prevalence and serves as an economic hub for the region, where residents from neighboring sub-counties converge to conduct business and sell goods and services. As such, the Namutumba sub-county represents a peri-urban environment that may promote the spread of $H$. pylori. This could also explain the finding that a higher level of education significantly correlated with $H$. pylori positivity, which appears to contradict previous findings ${ }^{11,39,40}$ but has been reported $^{8,41}$. Those living and working in a more urban setting such as the Namutumba sub-county may have attained a higher level of education compared to residents in more rural, less densely populated areas and who are predominantly subsistence farmers that may not have achieved the same level of education. Regardless, the regional variation in H. pylori prevalence identified in this study can allow public health officials to target certain "hot spots" within the district and to focus efforts on detection and eradication of $H$. pylori.

Despite the prevalence of $H$. pylori within our study population, its association with symptoms was inconsistent, in accordance with previous studies ${ }^{12,42}$. We found that the majority of H. pylori-positive participants experienced mild or no dyspepsia, as assessed by the SFLDQ. Indeed, there was no significant difference in the degree, frequency, or specificity of dyspeptic symptoms (i.e., heartburn, regurgitation, indigestion, nausea) between $H$. pylori-positive and -negative participants, highlighting $H$. pyloris variable and often mild symptomatology. Interestingly, the probability of being free of dyspepsia increased with age among $H$. pylori-positive participants, while the probability of experiencing severe dyspepsia was largely unchanged with respect to age. While the age of exposure or recurrent exposures to $H$. pylori were not assessed in this study, we would speculate that most of the H. pylori-positive participants have been chronically harboring H. pylori, ${ }^{43}, 44$ and our data would suggest that their dyspeptic symptoms wane over time. Whether the severity of dyspepsia is a result of more chronic $H$. pylori infection within this population remains to be seen, as the degree of gastritis was not 
endoscopically or histologically determined in H. pylori-positive participants. Nonetheless, the mild nature of symptoms may not have prompted infected participants to seek medical care, emphasizing the need for high clinical suspicion within this population. Based on our findings, if we estimate that approximately half of the Namutumba district harbors H. pylori, then we must acknowledge that a significant percentage of this population carries pre-neoplastic gastric lesions ${ }^{45}$ and is at risk of developing gastric cancer ${ }^{46}$.

The efficacy of $H$. pylori eradication in our study population using a standard triple therapy regimen was $89.7 \%$, in contrast to data showing a trend for declining cure rates $(\leq 80 \%)$ with triple therapy over the past two decades ${ }^{47-49}$. Current guidelines recommend the choice of therapy based on regional rates of antibiotic resistance 7 . Indeed, the rate of clarithromycin resistance within this region is not known, and the choice of standard, 14-day triple therapy was based on cost and availability. Within this study population, standard triple therapy was relatively effective and well tolerated. Moreover, the triple therapy regimen significantly improved dyspepsia among H. pylori-positive participants. Importantly, we noted that the likelihood of not eradicating $H$. pylori was significantly higher in participants who missed at least four doses during their treatment regimen. We did not ascertain whether those who failed treatment were colonized with $H$. pylori strains resistant to amoxicillin and/or clarithromycin. While it is established that poor compliance with therapy significantly reduces eradication efficacy 50,51 , the reasons for decreased compliance within our study population are unclear, though treatment failure did not seem to be associated with level of education, medication side effects, or the use of other medications during the treatment regimen.

The strengths of this study are multiple. To our knowledge, this is the first study that determined active $H$. pylori infection within a general (and primarily asymptomatic) adult population in sub-Saharan Africa. We identified hot spots for $H$. pylori positivity that can guide public health officials in targeting their prevention and treatment efforts. Most $H$. pylori-positive participants had mild to no dyspeptic symptoms, highlighting the need for heightened clinical suspicion for this common pathogen. We found that standard triple therapy was highly effective at eradicating $H$. pylori among medication-compliant participants. This study had several limitations. Rates of antibiotic resistance within this region were not determined ${ }^{23}, 52$. Given limited endoscopic and diagnostic resources within the Namutumba district, the prevalence of underlying gastric pre-neoplastic lesions was not assessed in $H$. pylori-positive residents. Similarly, the causes for dyspepsia in H. pylori-negative participants were not endoscopically investigated. It is possible that the high prevalence of dyspepsia among H. pylori-negative participants could be in part explained by gastroesophageal reflux disease (GERD), for example, which would not be distinguished by the SFLDQ alone. However, though the prevalence of dyspepsia within this population may appear high, this may be largely driven by the significant proportion of participants reporting mild dyspepsia. If we only consider the prevalence of moderate and severe dyspepsia, this may be more in line with rates of dyspepsia in prior population-based studies ${ }^{16,27}$. 
This study provides local policy makers with important data, including the prevalence of H. pylori infection, the frequency of dyspeptic symptoms, and the efficacy of triple therapy within this region. A previous study looking at dyspepsia in this region found that out of nine randomly selected health centers in the Namutumba District, none of the health centers had the capacity to test for H. pylori, and only two of the nine health centers prescribed appropriate triple therapy for clinically significant dyspepsia ${ }^{15}$. Moreover, unlicensed pharmacies provide approximately $40 \%$ of all healthcare to people in the Namutumba District ${ }^{53}$. Though diagnostic kits for $H$. pylori are relatively inexpensive ${ }^{36}$, instituting government-level policies to make these tests widely available and providing a standard of care for management of dyspeptic patients prior to empiric antibiotic usage would be a more effective method to appropriately manage $H$. pylori infection and limit antibiotic resistance. This study illustrates the effectiveness of population-based screening and eradication of $H$. pylori in sub-Saharan Africa. More importantly, it can serve as a template for future studies on the cost effectiveness of these measures for gastric cancer prevention in a resource-limited setting.

\section{Conclusions}

A population-based screening of a sub-Saharan African region found that $H$. pylori was prevalent, but $H$. pylori positivity in itself did not predict dyspeptic symptoms. This study highlights that clinical suspicion for $H$. pylori within this population should nonetheless remain high, given the high prevalence of positivity among all those with dyspepsia, including many with relatively mild dyspeptic symptoms. Populationbased screening and adherence to standard triple therapy are therefore effective at eradicating $H$. pylori within this region and should guide diagnosis and management of this chronic disease in a resourcelimited setting.

\section{Declarations}

\section{Ethics approval and consent to participate}

All study participants provided written informed consent. This study was approved by the Institutional Review Board at the Washington University in St. Louis School of Medicine (U.S.A.; IRB \# 201807047) and by the Ugandan National Council of Science and Technology (UNCST; approval \# HS305ES) and The AIDS Support Organization (TASO; Uganda; protocol \# TASOREC/002/18-UG-REC-009).

\section{Consent for publication}

Not applicable.

\section{Availability of data and materials}

The datasets used and/or analyzed during the current study are available from the corresponding author on reasonable request. 
Competing interests

The authors declare that they have no competing interests.

\section{Funding}

This study was entirely funded by a Faculty Diversity Scholars grant from the Washington University in St. Louis Department of Medicine (U.S.A.), awarded to José B. Sáenz. The funding body did not contribute to the design of the study or to the collection, analysis, or interpretation of data generated from this study.

\section{Authors' contributions}

YJL, IS, KR, TSB, PM, and JBS contributed to the design of the study. YJL, IS, KR, and TSB contributed to data collection. YW did the majority of the data analysis, with contributions from YJL, IS, KR, TSB, and JBS. YJL, IS, KR, TSB, YW, and JBS contributed to writing and editing the final manuscript.

\section{$\underline{\text { Acknowledgments }}$}

The authors wish to acknowledge David Alpers (Washington University in St. Louis School of Medicine), Greg Sayuk (Washington University in St. Louis School of Medicine), and Merlin Wilcox (University of Southampton) for critical review of the manuscript, Malcolm Katusabe, Ritah Namutamba, Sumaiyah Nakaziba, and Angel Mutesi for data collection, and Joshua Sills for assistance with figure design.

\section{References}

1. Hooi JKY, Lai WY, Ng WK, et al. Global Prevalence of Helicobacter pylori Infection: Systematic Review and Meta-Analysis. Gastroenterology. 2017;153:420-9.

2. Saenz JB, Mills JC. Acid and the basis for cellular plasticity and reprogramming in gastric repair and cancer. Nat Rev Gastroenterol Hepatol. 2018;15:257-73.

3. Schistosomes, liver flukes and Helicobacter pylori. IARC Working Group on the Evaluation of Carcinogenic Risks to Humans. Lyon, 7-14 June 1994. IARC Monogr Eval Carcinog Risks Hum. 1994;61:1-241.

4. Bray F, Ferlay J, Soerjomataram I, et al. Global cancer statistics 2018: GLOBOCAN estimates of incidence and mortality worldwide for 36 cancers in 185 countries. CA Cancer J Clin. 2018;68:394424.

5. Graham DY. Helicobacter pylori update: gastric cancer, reliable therapy, and possible benefits. Gastroenterology. 2015;148:719-31. e3.

6. Salih BA. Helicobacter pylori infection in developing countries: the burden for how long? Saudi J Gastroenterol. 2009;15:201-7. 
7. El-Serag HB, Kao JY, Kanwal F, et al. Houston Consensus Conference on Testing for Helicobacter pylori Infection in the United States. Clin Gastroenterol Hepatol 2018;16:992-1002 e6.

8. Aminde JA, Dedino GA, Ngwasiri CA, et al. Helicobacter pylori infection among patients presenting with dyspepsia at a primary care setting in Cameroon: seroprevalence, five-year trend and predictors. BMC Infect Dis. 2019;19:30.

9. Archampong TN, Asmah RH, Wiredu EK, et al. Epidemiology of Helicobacter pylori infection in dyspeptic Ghanaian patients. Pan Afr Med J. 2015;20:178.

10. Bakka AS, El-Gariani AB, AbouGhrara FM, et al. Frequency of Helicobacter pylori infection in dyspeptic patients in Libya. Saudi Med J. 2002;23:1261-5.

11. Tsongo L, Nakavuma J, Mugasa C, et al. Helicobacter pylori among patients with symptoms of gastroduodenal ulcer disease in rural Uganda. Infect Ecol Epidemiol. 2015;5:26785.

12. Rosenstock S, Kay L, Rosenstock C, et al. Relation between Helicobacter pylori infection and gastrointestinal symptoms and syndromes. Gut. 1997;41:169-76.

13. Moayyedi P. The health economics of Helicobacter pylori infection. Best Pract Res Clin Gastroenterol. 2007;21:347-61.

14. Moayyedi PM, Lacy BE, Andrews CN, et al. ACG and CAG Clinical Guideline: Management of Dyspepsia. Am J Gastroenterol. 2017;112:988-1013.

15. Lee YJ, Adusumilli G, Kyakulaga F, et al. Survey on the prevalence of dyspepsia and practices of dyspepsia management in rural Eastern Uganda. Heliyon. 2019;5:e01644.

16. Seid A, Tamir Z, Demsiss W. Uninvestigated dyspepsia and associated factors of patients with gastrointestinal disorders in Dessie Referral Hospital, Northeast Ethiopia. BMC Gastroenterol. 2018;18:13.

17. Kouitcheu Mabeku LB, Noundjeu Ngamga ML, Leundji H. Potential risk factors and prevalence of Helicobacter pylori infection among adult patients with dyspepsia symptoms in Cameroon. BMC Infect Dis. 2018;18:278.

18. Asrat D, Nilsson I, Mengistu Y, et al. Prevalence of Helicobacter pylori infection among adult dyspeptic patients in Ethiopia. Ann Trop Med Parasitol. 2004;98:181-9.

19. Olokoba AB, Apari E, Salawu FK, et al. Helicobacter pylori indyspeptic Nigerians. West Afr J Med. 2013;32:277-80.

20. Jemilohun AC, Otegbayo JA, Ola SO, et al. Prevalence of Helicobacter pylori among Nigerian patients with dyspepsia in Ibadan. Pan Afr Med J. 2010;6:18.

21. Kasew D, Abebe A, Munea U, et al. Magnitude of Helicobacter pylori among Dyspeptic Patients Attending at University of Gondar Hospital, Gondar, Northwest Ethiopia. Ethiop J Health Sci. 2017;27:571-80.

22. Shmuely H, Obure S, Passaro DJ, et al. Dyspepsia symptoms and Helicobacter pylori infection, Nakuru, Kenya. Emerg Infect Dis. 2003;9:1103-7. 
23. Tanih NF, Dube C, Green E, et al. An African perspective on Helicobacter pylori: prevalence of human infection, drug resistance, and alternative approaches to treatment. Ann Trop Med Parasitol. 2009;103:189-204.

24. Anker M. Epidemiological and statistical methods for rapid health assessment: introduction. World Health Stat Q. 1991;44:94-7.

25. Fraser A, Delaney BC, Ford AC, et al. The Short-Form Leeds Dyspepsia Questionnaire validation study. Aliment Pharmacol Ther. 2007;25:477-86.

26. Crowe SE. Helicobacter pylori Infection. N Engl J Med. 2019;380:1158-65.

27. Bitwayiki R, Orikiiriza JT, Kateera F, et al. Dyspepsia prevalence and impact on quality of life among Rwandan healthcare workers: A cross-sectional survey. S Afr Med J. 2015;105:1064-9.

28. Moayyedi P, Forman D, Braunholtz D, et al. The proportion of upper gastrointestinal symptoms in the community associated with Helicobacter pylori, lifestyle factors, and nonsteroidal anti-inflammatory drugs. Leeds HELP Study Group. Am J Gastroenterol. 2000;95:1448-55.

29. Abebaw W, Kibret M, Abera B. Prevalence and risk factors of $H$. pylori from dyspeptic patients in northwest Ethiopia: a hospital based cross-sectional study. Asian Pac J Cancer Prev. 2014;15:445963.

30. Darko R, Yawson AE, Osei V, et al. Changing Patterns of the Prevalence of Helicobacter Pylori Among Patients at a Corporate Hospital in Ghana. Ghana Med J. 2015;49:147-53.

31. Deaton AS, Tortora R. People in sub-Saharan Africa rate their health and health care among the lowest in the world. Health Aff (Millwood). 2015;34:519-27.

32. Marsh RH, Rouhani SA. Gaps in physical access to emergency care in sub-Saharan Africa. Lancet Glob Health. 2018;6:e240-1.

33. Best LM, Takwoingi Y, Siddique S, et al. Non-invasive diagnostic tests for Helicobacter pylori infection. Cochrane Database Syst Rev. 2018;3:CD012080.

34. Segamwenge IL, Kagimu M, Ocama P, et al. The utility of the Helicobacter pylori stool antigen test in managing dyspepsia: an experience from a low resource setting. Afr Health Sci. 2014;14:829-34.

35. Kazemi S, Tavakkoli H, Habizadeh MR, et al. Diagnostic values of Helicobacter pylori diagnostic tests: stool antigen test, urea breath test, rapid urease test, serology and histology. J Res Med Sci. 2011;16:1097-104.

36. Elwyn G, Taubert M, Davies S, et al. Which test is best for Helicobacter pylori? A cost-effectiveness model using decision analysis. Br J Gen Pract. 2007;57:401-3.

37. Ontsira Ngoyi EN, Atipo Ibara BI, Moyen R, et al. Molecular Detection of Helicobacter pylori and its Antimicrobial Resistance in Brazzaville. Congo Helicobacter. 2015;20:316-20.

38. Kimang'a AN, Revathi G, Kariuki S, et al. Helicobacter pylori: prevalence and antibiotic susceptibility among Kenyans. S Afr Med J. 2010;100:53-7.

39. Zhu Y, Zhou X, Wu J, et al. Risk Factors and Prevalence of Helicobacter pylori Infection in Persistent High Incidence Area of Gastric Carcinoma in Yangzhong City. Gastroenterol Res Pract. 
2014;2014:481365.

40. Genta RM, Turner KO, Sonnenberg A. Demographic and socioeconomic influences on Helicobacter pylori gastritis and its pre-neoplastic lesions amongst US residents. Aliment Pharmacol Ther. 2017;46:322-30.

41. Yan TL, Hu QD, Zhang Q, et al. National rates of Helicobacter pylori recurrence are significantly and inversely correlated with human development index. Aliment Pharmacol Ther. 2013;37:963-8.

42. Nandurkar S, Talley NJ, Xia H, et al. Dyspepsia in the community is linked to smoking and aspirin use but not to Helicobacter pylori infection. Arch Intern Med. 1998;158:1427-33.

43. Rowland M, Daly L, Vaughan M, et al. Age-specific incidence of Helicobacter pylori. Gastroenterology. 2006;130:65-72. quiz 211.

44. Rowland M, Clyne M, Daly L, et al. Long-term follow-up of the incidence of Helicobacter pylori. Clin Microbiol Infect. 2018;24:980-4.

45. Correa P, Piazuelo MB. The gastric precancerous cascade. J Dig Dis. 2012;13:2-9.

46. Asombang AW, Rahman R, Ibdah JA. Gastric cancer in Africa: current management and outcomes. World J Gastroenterol. 2014;20:3875-9.

47. Graham DY, Lee YC, Wu MS. Rational Helicobacter pylori therapy: evidence-based medicine rather than medicine-based evidence. Clin Gastroenterol Hepatol. 2014;12:177-86. e3; Discussion e12-3.

48. Graham DY, Fischbach LA. Empiric therapies for Helicobacter pylori infections. CMAJ. 2011;183:E506-8.

49. Kabakambira JD, Hategeka C, Page C, et al. Efficacy of Helicobacter pylori eradication regimens in Rwanda: a randomized controlled trial. BMC Gastroenterol. 2018;18:134.

50. Graham DY, Lew GM, Malaty HM, et al. Factors influencing the eradication of Helicobacter pylori with triple therapy. Gastroenterology. 1992;102:493-6.

51. Lee $\mathrm{M}, \mathrm{Kemp} \mathrm{JA}$, Canning A, et al. A randomized controlled trial of an enhanced patient compliance program for Helicobacter pylori therapy. Arch Intern Med. 1999;159:2312-6.

52. Angol DC, Ocama P, Ayazika Kirabo T, et al. Helicobacter pylori from Peptic Ulcer Patients in Uganda Is Highly Resistant to Clarithromycin and Fluoroquinolones: Results of the GenoType HelicoDR Test Directly Applied on Stool. Biomed Res Int. 2017;2017:5430723.

53. Lee YJ, Adusumilli G, Kazungu R, et al. Treatment-seeking behavior and practices among caregivers of children aged $</=5$ y with presumed malaria in rural Uganda. Trans R Soc Trop Med Hyg 2019.

\section{Figures}


Figure 1.

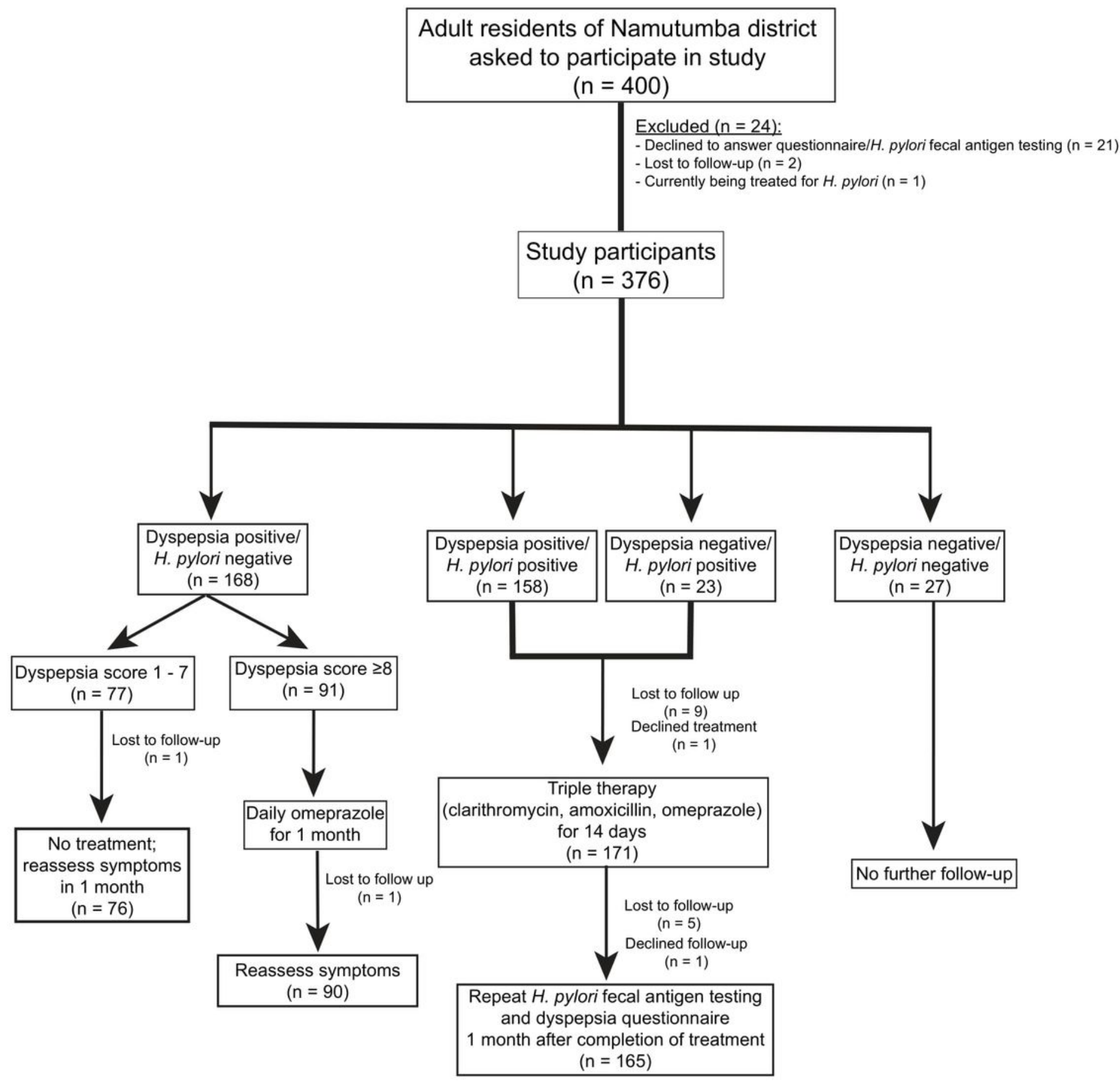

Figure 1

Study design. 
Figure 2.

A)

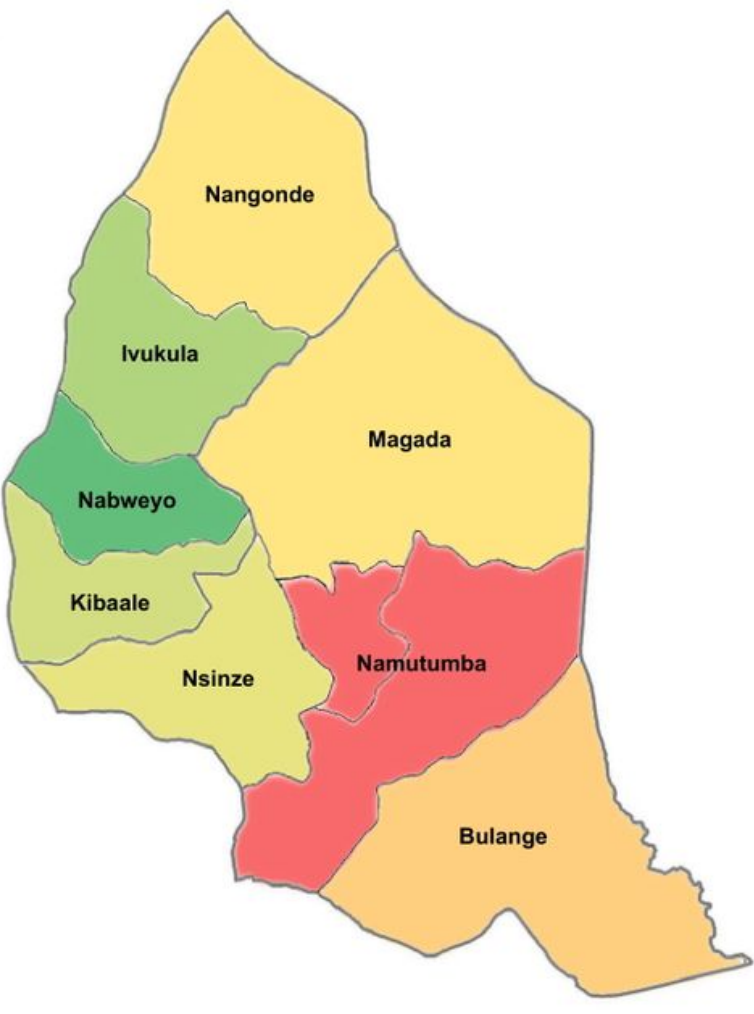

Number of $\boldsymbol{H}$. pylori positive participants

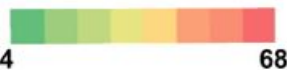

B)

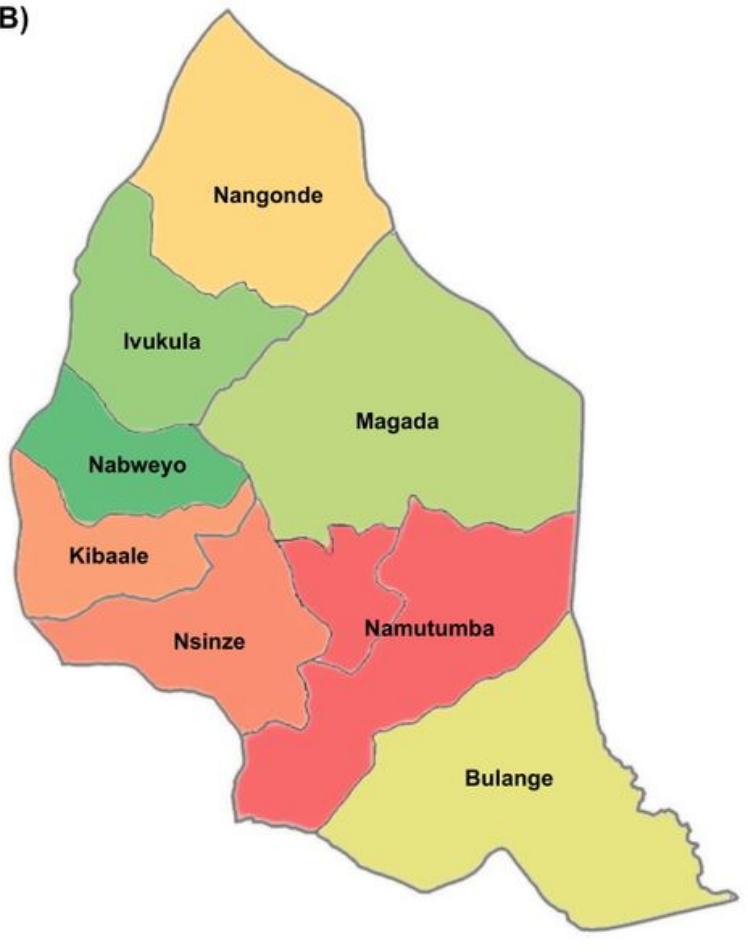

Percent $\boldsymbol{H}$. pyori positive participants (normalized to number sampled)

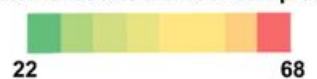

\section{Figure 2}

Distribution of Helicobacter pylori (H. pylori) within the Namutumba District. The map of Namutumba District sub-counties was obtained from the Uganda Bureau of Statistics (2017), The National Population and Housing Census 2014 - Area Specific Profile Series, Kampala, Uganda. 
Figure 3.

\section{All Participants $(n=376)$}

A)

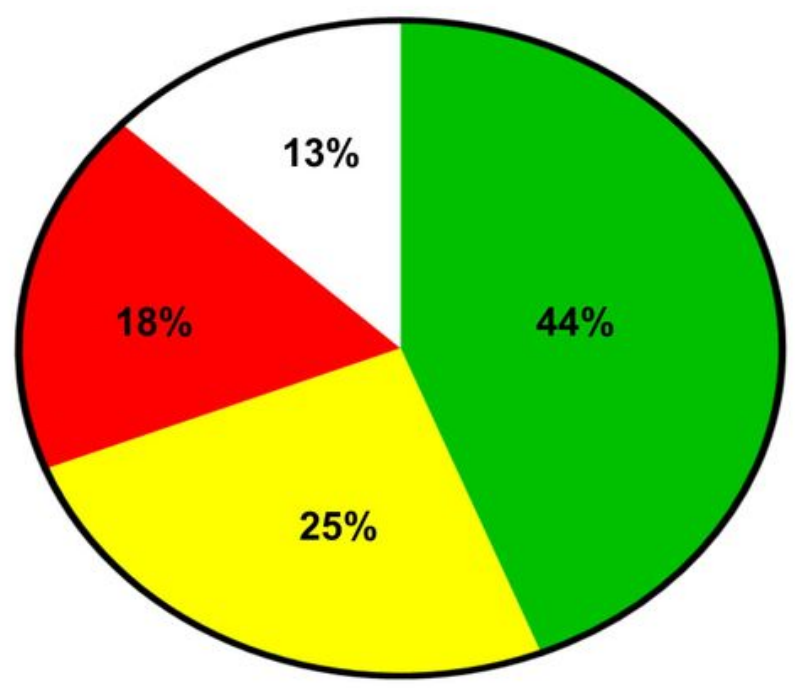

B)

C)

\section{H. pylori-Negative $(n=195)$}

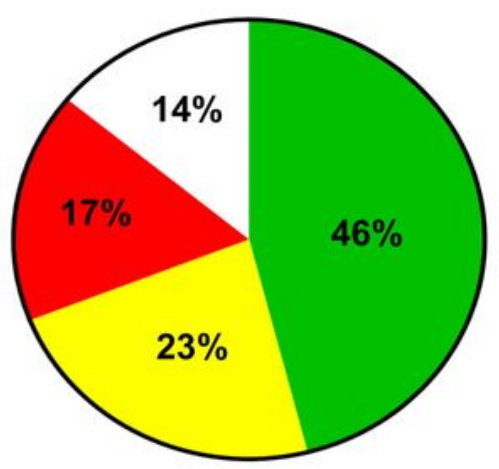

H. pylori-Positive $(n=181)$

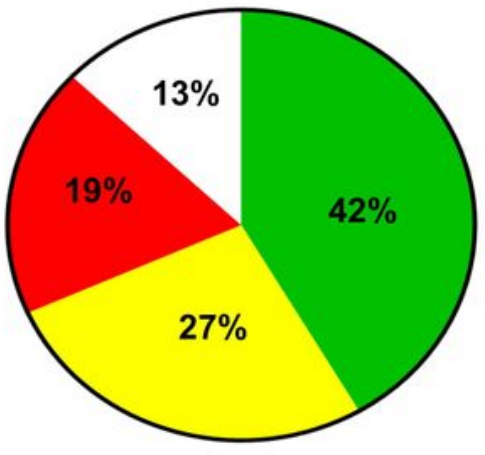

Severity of Dyspepsia (score)

Mild $(1-8)$
Moderate $(9-15)$
Severe $(>15)$
$\square$ None $(0)$

H. pylori: Helicobacter pylori

Figure 3

Distribution of dyspepsia severity. 
Figure 4.

A)

All participants

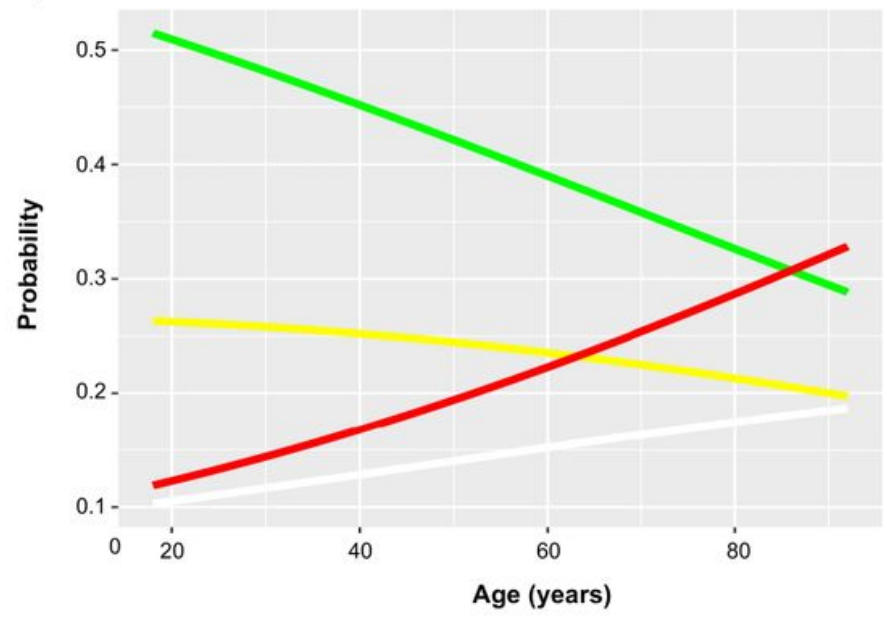

Dyspepsia severity (SFLDQ* score)

$\square$ None $(0)$

Mild (1 - 8)

$\square$ Moderate (9 - 15)

Severe (>15)

B)

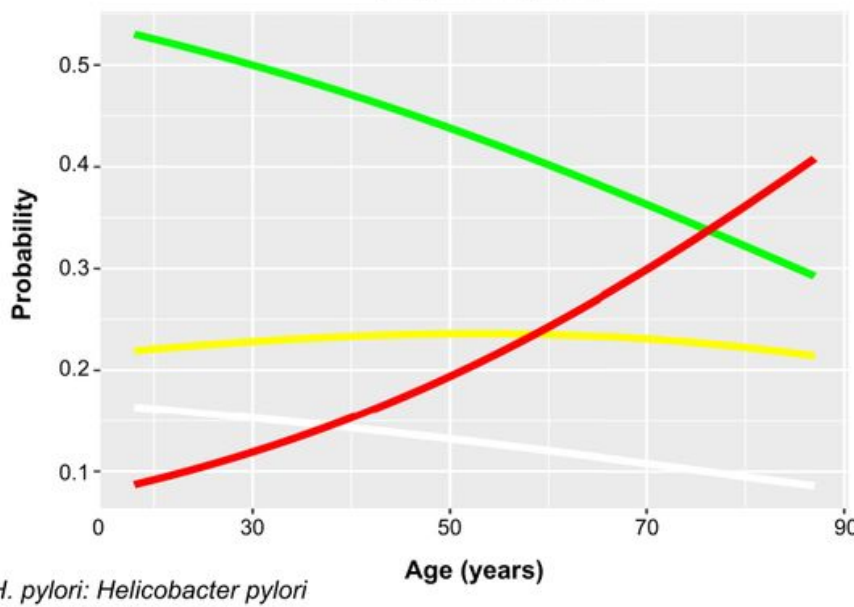

C)

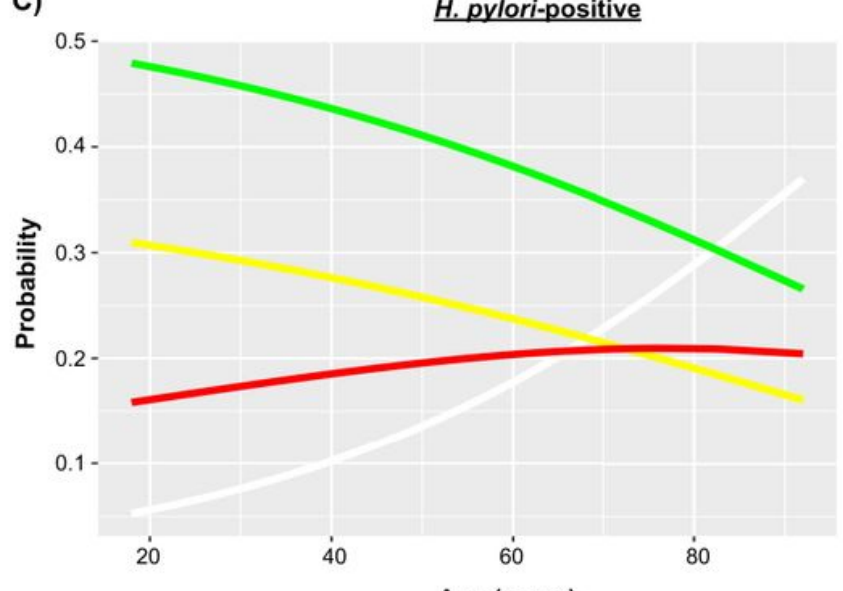

Age (years)

\section{Figure 4}

Relationship between dyspepsia severity and age.

Figure 5.
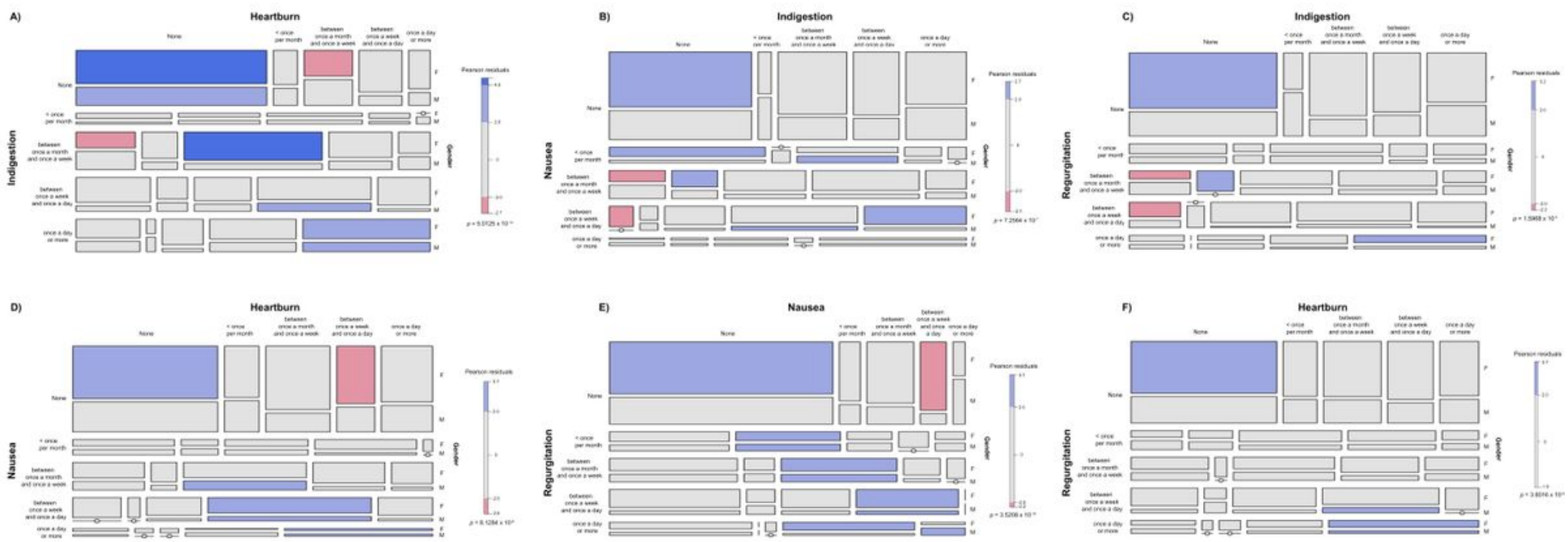

\section{Figure 5}


Correlation between dyspeptic symptoms.

Figure 6.
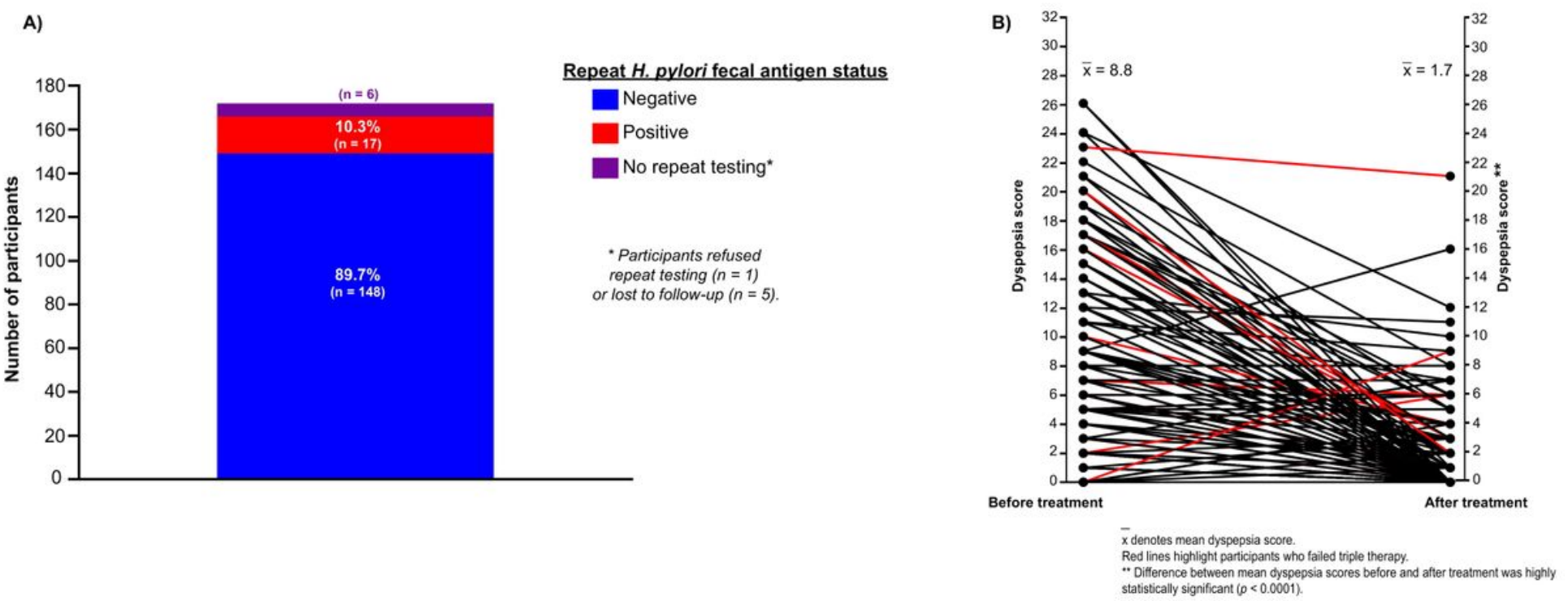

Figure 6

Efficacy of triple therapy on Helicobacter pylori $(\mathrm{H}$. pylori) eradication and improvement in dyspepsia.

\section{Supplementary Files}

This is a list of supplementary files associated with this preprint. Click to download.

- CONSORT2010ChecklistJBS.docx

- SupplementalFigure1final.pdf

- SupplementalTable5.docx

- SupplementalTable4.docx

- SupplementalTable3.docx

- SupplementalTable2.docx

- SupplementalTable1.docx 